\title{
Helping everyone do better: a call for validation studies of routinely recorded health data
}

This article was published in the following Dove Press journal:

Clinical Epidemiology

12 April 2016

Number of times this article has been viewed

\author{
Vera Ehrenstein' \\ Irene Petersen ${ }^{1,2}$ \\ Liam Smeeth ${ }^{3}$ \\ Susan S Jick ${ }^{4}$ \\ Eric I Benchimol ${ }^{5,6}$ \\ Jonas F Ludvigsson ${ }^{7,8}$ \\ Henrik Toft Sørensen ${ }^{1}$ \\ 'Department of Clinical Epidemiology, \\ Aarhus University Hospital, \\ Aarhus, Denmark; '²Department \\ of Primary Care and Population \\ Health, University College London, \\ London, UK; ${ }^{3}$ Department of \\ Non-Communicable Disease \\ Epidemiology, London School of \\ Hygiene and Tropical Medicine, \\ London, UK; ${ }^{4}$ Boston Collaborative \\ Drug Surveillance Program, Boston \\ University School of Public Health, \\ Boston, MA, USA; ${ }^{5}$ Department of \\ Pediatrics and School of Epidemiology, \\ Public Health and Preventive \\ Medicine, Faculty of Medicine, \\ University of Ottawa, Ottawa, \\ ON, Canada; ${ }^{6}$ nstitute for Clinical \\ Evaluative Sciences, Toronto, ON, \\ Canada; ${ }^{7}$ Department of Medical \\ Epidemiology and Biostatistics, \\ Karolinska Institutet, Stockholm, \\ ${ }^{8}$ Department of Pediatrics, University \\ Hospital of Örebro, Sweden
}

Correspondence: Vera Ehrenstein Department of Clinical Epidemiology, Aarhus University Hospital, 43-45 Olof Palmes Allé, 8200 N Aarhus, Denmark Email ve@clin.au.dk
There has been a surge of availability and use for research of routinely collected electronic health data, such as electronic health records, health administrative data, and disease registries. Symptomatic of this surge, in 2012, Pharmacoepidemiology and Drug Safety (PDS) published a supplemental issue containing several reviews of validated methods for identifying health outcomes using routine health data, ${ }^{1}$ focusing on databases feeding the US Mini-Sentinel Program. ${ }^{2}$ In one of the review papers of the PDS Supplement, Carnahan ${ }^{3}$ acknowledged that while ample validated algorithms exist for major health events, for example, cardiovascular events, validated methods of identifying many health outcomes are lacking. Furthermore, the referenced studies focused on algorithms based on coding sets used in the United States (eg, ICD-9) to identify events from US databases, set within the US health care system. This leaves out an entire segment of routine databases, most notably, Nordic national registries or other European databases such as Clinical Practice Research Datalink (CPRD), The Heatlh Improvement Network (THIN) Hospital Episode Statistics (HES), or PHARMO, all of which are set in health care systems that are differently run and financed than those in the United States. Since other systems function differently, and the databases contain different variables, validation of health status in US data may not always be generalizable..$^{5-9}$ Many validation studies have been done among these various resources, ${ }^{10-12}$ but the work is far from complete, as shown in a systematic review of validation studies of the UK-based Clinical Practice Research Datalink, published in 2010. ${ }^{13}$ Some algorithms may become outdated because of changes in coding or medical practices; new diseases, without clear representation in classification systems, may emerge. Furthermore, in October 2015, the United States adopted ICD- $10,{ }^{14}$ while ICD-11 is looming on the horizon. ${ }^{15}$

Clinical Epidemiology has published and continues to publish studies that describe the validity of algorithms in routinely recorded health data, such as validation of medication use in hospitals, ${ }^{16,17}$ cancer characteristics and complications, ${ }^{18-20}$ or events related to reproductive and fetal medicine, ${ }^{21,22}$ to name just a few examples. An "algorithm" in the present context refers to a combination of values of routinely collected variables that allow identification of cases of a given disease or other health event without having to contact or examine the patient. For example, an algorithm based on a combination of diagnostic ICD-10 codes E10-E11 and medication ATC 
codes A10 may identify patients with diabetes. The commonly evaluated aspects of an algorithm's validity are positive predictive value (proportion of algorithm-positive patients who truly have the disease of interest) and sensitivity (proportion of patients with the disease of interest who are algorithm-positive), and their counterparts negative predictive value (proportion of algorithm-negative persons without the disease of interest) and specificity (proportion of persons without the disease who are algorithm-negative). Validity of entire data sources is commonly measured by their completeness (proportion of true cases of a disease captured by a data source). A comprehensive review of methods for validating algorithms to identify disease cohorts from health administrative data, with accompanying reporting guidelines for such work, was published by the Journal of Clinical Epidemiology in 2011. ${ }^{23}$

Clinical Epidemiology is hereby issuing a targeted call for papers that report on results of validation studies. We are interested in publishing both original validation studies and systematic reviews, using various types of reference ("gold") standards, such as review of medical charts or comparison with other data sources. Several resources are available to guide reporting, including the 2011 guidelines mentioned above, ${ }^{23}$ as well as the STARD Checklist, ${ }^{24}$ and the RECORD Checklist. ${ }^{25,26}$ Please take advantage of these resources in preparing your high-quality submissions.

Some may think of validation work as mundane, a mere poor relative of the "real" original research. We subscribe to a different viewpoint. First, misclassification of study variables threatens the validity of research findings. ${ }^{27}$ Since epidemiologic research is "an exercise in measurement", ${ }^{28}$ high-quality original research is unthinkable without accurate or accurately calibrated instruments. In our editorial experience, evidence of data validity is routinely requested by article referees. Second, following from above, results of validation studies allow epidemiologists to assess the extent of misclassification and estimate its impact on the study results. Third, shining the spotlight on validation studies may activate a feedback loop: physicians may become even more motivated to use systematic coding schemes keeping in mind that the data they feed into the routine databases will be used for research that will ultimately benefit their patients. Last, but not least, validation studies are frequently cited. For example, systematic reviews by Khan et $\mathrm{al}^{29}$ and Herrett et al, ${ }^{13}$ published in 2010, have already received more than 240 and 350 citations, respectively. We hope you find our arguments compelling and look forward to receiving your validation study submissions.

\section{Disclosure}

The authors report no conflict of interest in this work.

\section{References}

1. Pharmacoepidemiology and Drug Safety. Available from: http:// onlinelibrary.wiley.com/doi/10.1002/pds.v21.S1/issuetoc. Accessed January 20, 2016.

2. Mini-Sentinel. Available from: http://www.mini-sentinel.org/. Accessed December 7, 2015.

3. Carnahan RM. Mini-Sentinel's systematic reviews of validated methods for identifying health outcomes using administrative data: summary of findings and suggestions for future research. Pharmacoepidemiol Drug Saf. 2012;21:90-99.

4. PHARMO. Available from: http://www.pharmo.nl/. Accessed December 9, 2015.

5. Hsing AW, Ioannidis JP. Nationwide population science: lessons from the Taiwan National Health Insurance Research Database. JAMA Intern Med. 2015;175(9):1527-1529.

6. Coloma PM, Schuemie MJ, Trifiro G, et al. Combining electronic healthcare databases in Europe to allow for large-scale drug safety monitoring: the EU-ADR Project. Pharmacoepidemiol Drug Saf. 2011;20(1):1-11.

7. Trifiro G, Coloma PM, Rijnbeek PR, et al. Combining multiple healthcare databases for postmarketing drug and vaccine safety surveillance: why and how? J Intern Med. 2014;275(6):551-561.

8. Wettermark B, Zoega H, Furu K, et al. The Nordic prescription databases as a resource for pharmacoepidemiological research - a literature review. Pharmacoepidemiol Drug Saf. 2013;22(7):691-699.

9. Schmidt M, Pedersen L, Sorensen HT. The Danish Civil Registration System as a tool in epidemiology. Eur J Epidemiol. 2014;29(8): 541-549.

10. Schmidt M, Schmidt SA, Sandegaard JL, Ehrenstein V, Pedersen L, Sorensen HT. The Danish National Patient Registry: a review of content, data quality, and research potential. Clin Epidemiol. 2015;7:449-490.

11. Ludvigsson J, Andersson E, Ekbom A, et al. External review and validation of the Swedish national inpatient register. BMC Public Health. 2011;11(1):450.

12. Jick SS, Kaye JA, Vasilakis-Scaramozza C, et al. Validity of the general practice research database. Pharmacotherapy. 2003;23(5):686-689.

13. Herrett E, Thomas SL, Schoonen WM, Smeeth L, Hall AJ. Validation and validity of diagnoses in the General Practice Research Database: a systematic review. Br J Clin Pharmacol. 2010;69(1):4-14.

14. Centers for Medicare and Medicaid Services. Available from: https:// www.cms.gov/Newsroom/MediaReleaseDatabase/Press-releases/2014Press-releases-items/2014-07-31.html. Accessed December 9, 2015.

15. ICD-11 Beta Draft. Available from: http://apps.who.int/classifications/ icd11/browse/1-m/en. Accessed December 7, 2015.

16. Lund JL, Froslev T, Deleuran T, et al. Validity of the Danish National Registry of Patients for chemotherapy reporting among colorectal cancer patients is high. Clin Epidemiol. 2013;5:327-334.

17. Nielsson MS, Erichsen R, Froslev T, Taylor A, Acquavella J, Ehrenstein V. Positive predictive values of the coding for bisphosphonate therapy among cancer patients in the Danish National Patient Registry. Clin Epidemiol. 2012;4:233-236.

18. Bergdahl J, Jarnbring F, Ehrenstein V, et al. Evaluation of an algorithm ascertaining cases of osteonecrosis of the jaw in the Swedish National Patient Register. Clin Epidemiol. 2013;5:1-7.

19. Deleuran T, Sogaard M, Froslev T, et al. Completeness of TNM staging of small-cell and non-small-cell lung cancer in the Danish cancer registry, 2004-2009. Clin Epidemiol. 2012;4:39-44.

20. Jensen AO, Norgaard M, Yong M, Fryzek JP, Sorensen HT. Validity of the recorded International Classification of Diseases, 10th edition diagnoses codes of bone metastases and skeletal-related events in breast and prostate cancer patients in the Danish National Registry of Patients. Clin Epidemiol. 2009;1:101-108. 
21. Thygesen SK, Olsen M, Christian FC. Positive predictive value of the infant respiratory distress syndrome diagnosis in the Danish National Patient Registry. Clin Epidemiol. 2013;5:295-298.

22. Lohse SR, Farkas DK, Lohse N, et al. Validation of spontaneous abortion diagnoses in the Danish National Registry of Patients. Clin Epidemiol. 2010;2:247-250.

23. Benchimol EI, Manuel DG, To T, Griffiths AM, Rabeneck L, Guttmann A. Development and use of reporting guidelines for assessing the quality of validation studies of health administrative data. J Clin Epidemiol. 2011;64(8):821-829.

24. STARD Checklist. Available from: http://www.equator-network.org/ reporting-guidelines/stard/. Accessed December 9, 2015.

25. RECORD Checklist. Available from: http://www.equator-network.org/ reporting-guidelines/record/. Accessed December 9, 2015.
26. Benchimol EI, Smeeth L, Guttmann A, et al. The REporting of studies Conducted using Observational Routinely-collected health Data (RECORD) statement. PLoS Med. 2015;12(10):e1001885.

27. Manuel DG, Rosella LC, Stukel TA. Importance of accurately identifying disease in studies using electronic health records. $B M J$. 2010;341:c4226.

28. Rothman KJ, Greenland S. Causation and causal inference in epidemiology. Am J Public Health. 2005;95(Suppl 1):S144-S150.

29. Khan NF, Harrison SE, Rose PW. Validity of diagnostic coding within the General Practice Research Database: a systematic review. Br J Gen Pract. 2010;60(572):e128-e136.

Dove Medical Press encourages responsible, free and frank academic debate. The content of the Clinical Epidemiology 'Editorial' section does not necessarily represent the views of Dove Medical Press, its officers, agents, employees, related entities or the Clinical Epidemiology editors. While all reasonable steps have been taken to confirm the content of each Editorial, Dove Medical Press accepts no liability in respect of the content of any Editorial, nor is it responsible for the content and accuracy of any Editorial.

Clinical Epidemiology

\section{Publish your work in this journal}

Clinical Epidemiology is an international, peer-reviewed, open access, online journal focusing on disease and drug epidemiology, identification of risk factors and screening procedures to develop optimal preventative initiatives and programs. Specific topics include: diagnosis, prognosis, treatment, screening, prevention, risk factor modification,

Submit your manuscript here: http://www.dovepress.com/clinical-epidemiology-journal

\section{Dovepress}

systematic reviews, risk \& safety of medical interventions, epidemiology \& biostatistical methods, and evaluation of guidelines, translational medicine, health policies \& economic evaluations. The manuscript management system is completely online and includes a very quick and fair peer-review system, which is all easy to use. 